\title{
Use of professional practice guidance resources in pharmacy: a cross-sectional nationwide survey of pharmacists, intern pharmacists, and pharmacy students
}

\author{
Deanna Mill1* ${ }^{*}$, Jacinta L. Johnson ${ }^{2,3}$, Kenneth Lee $^{1}$, Sandra M. Salter ${ }^{1}$, Danielle D'Lima ${ }^{4}$, Liza Seubert ${ }^{1}$,
} Rhonda Clifford ${ }^{1}$ and Amy T. Page P,5,6 $^{1,3}$

\begin{abstract}
Background: Variations in practice are commonplace in healthcare where health professionals, such as pharmacists act as autonomous practitioners. This is evident in simulated patient studies, where pharmacists practice does not meet widely accepted standards for medicines supply or treatment of an ailment. To promote best pharmacy practice a myriad of guidance resources including practice guidelines, codes and standards are produced by professional organisations. These resources provide a framework for pharmacy practice and endeavour to facilitate consistency in provision of pharmacy-based services to consumers. Despite their role in specifying essential pharmacist behaviours, there is limited research exploring if and how these resources are used in practice.

Objective: To characterise Australian pharmacists' use of the Pharmaceutical Society of Australia's Code of Ethics, Professional Practice Guidelines and Professional Practice Standards.

Methods: A cross-sectional, self-administered, electronic survey of registered pharmacists, intern pharmacists and pharmacy students living in Australia was conducted in July 2020. Questions considered use of professional practice resources (by resource group) in the preceding 12 months. Data were analysed descriptively.

Results: Of 601 responses included in the analysis 462 (76.9\%) of respondents were registered pharmacists, 88 (14.6\%) pharmacy students and 51 (8.5\%) intern pharmacists. Interns and students accessed overarching practice resources, such as the Professional Practice Standards, Code of Ethics and Dispensing Practice Guidelines more frequently than practising pharmacists. Pharmacists accessed professional practice guidelines, such as Practice Guidelines for the Provision of Immunisation Services Within Pharmacy, more often than students. More pharmacists than interns and students indicated that they would access guidelines to resolve practice and patient care issues. All resources except the Professional Practice Standards for Pharmacists (67.4\%) were accessed by less than 50\% of respondents in the preceding 12-month period. Reasons for not accessing resources varied between participant and resource groups, and generally were due to a lack of awareness of the resource or not considering them necessary for the individual's practice.
\end{abstract}

Editorial responsibility: Zaheer Babar, University of Huddersfield, UK.

${ }^{*}$ Correspondence: Deanna.Mill@research.uwa.edu.au

'School of Allied Health, The University of Western Australia, Perth, WA, Australia

Full list of author information is available at the end of the article permits use, sharing, adaptation, distribution and reproduction in any medium or format, as long as you give appropriate credit to the original author(s) and the source, provide a link to the Creative Commons licence, and indicate if changes were made. The images or other third party material in this article are included in the article's Creative Commons licence, unless indicated otherwise in a credit line to the material. If material is not included in the article's Creative Commons licence and your intended use is not permitted by statutory regulation or exceeds the permitted use, you will need to obtain permission directly from the copyright holder. To view a copy of this licence, visit http://creativecommons.org/licenses/by/4.0/. The Creative Commons Public Domain Dedication waiver (http://creativeco mmons.org/publicdomain/zero/1.0/) applies to the data made available in this article, unless otherwise stated in a credit line to the data. 
Conclusion(s): Access and use patterns for professional practice guidance resources change with experience. Professional organisations responsible for developing resources should consider these patterns when designing and reviewing resources and related policies. To ensure resources are meeting the needs of the profession, students, interns, and pharmacists should be involved in the review of and design of further resources.

\section{Highlights}

- Pharmacy students access core guidance resources more than practising pharmacists.

- Pharmacists and interns access service specific resources more than students.

- Most resources were accessed by less than half of respondents in a 12-month period.

- Resources used to update knowledge, check practice and improve resource familiarity.

- Irrelevant content, no perceived need for information and poor awareness limited use.

Keywords: Pharmacist, Practice standards, Code of ethics, Practice guidelines, Professional behaviour

\section{Background}

Practice standards, codes of conduct and practice guidelines exist to communicate the expected minimum conduct of pharmacists when they are providing care to patients [1-4]. These key professional guidance resources allow professional and regulatory bodies to communicate the legal, ethical and professional requirements that must be adhered to when a pharmacist provides patient care [1-3]. Professional practice guidance resources differ regarding their specific aims and purpose. 'Codes' typically dictate high level principles that should be considered by the professional regardless of area of practice (e.g., do no harm) [2, 4], 'practice standards' communicate expected behaviours of the profession (e.g., provide medicines information to all patients when dispensing their prescriptions) [1] and 'practice guidelines' provide specific advice around the steps needed to provide a medicine or service (e.g., vaccination service) $[3,5]$.

Given pharmacists are autonomous professionals some variations in provision of care are expected. Previously published simulated patient scenario studies, descriptions of disciplinary hearings and studies exploring pharmacists' navigation of ethical scenarios highlight that these inconsistencies, when compared to practice recommended in guidance resources, can lead to suboptimal patient care [6-16]. Such suboptimal practice and professional transgressions have included inappropriate storage and supply of scheduled medicines (e.g., without adequate medicines counselling), inappropriate disposal of medicines and inappropriate referrals to other health professionals [6-16]. Adhering to the recommendations in these practice guidance resources should enable pharmacists to ensure they provide, consistent, quality services to all patients. Practice guidelines function to educate pharmacists to enable consistent service provision, and also to ensure that service provision to patients is evidenced based, safe, effective, and adheres to legal and ethical practice requirements $[3,17]$. These resources can provide guidance to pharmacists when they do not know how to proceed in a specific situation or need to clarify their responsibilities. Professional practice guidance resources can also be used to help individuals reflect on their own practice, to provide guidance in the provision of services, for the public to understand what they can expect from a pharmacist, to outline the expectations of providing a service that is reimbursed by the government or another funder, and occasionally in instances of investigating malpractice $[1,4]$. Professional practice guidance resources are, therefore, generally introduced to pharmacy students and intern pharmacists as part of their education and professional socialisation.

Given professional practice guidance resources are essential for ensuring quality pharmaceutical care, the International Pharmaceutical Federation have recommended their member associations make them a priority to ensure pharmacists in their respective countries have access to adequate guidance $[18,19]$. The Pharmaceutical Society of Australia (PSA), the peak national body representing Australian pharmacists, continually develop professional practice guidance resources for the pharmacy profession. These resources are usually developed in collaboration with or endorsed by government agencies, regulatory authorities and other relevant organisations (e.g., the Pharmacy Guild of Australia or Consumers Health Forum of Australia) $[1,5,20]$. These organisations invest considerable time and money to develop these professional practice guidance resources, with the intention that they will support consistency and quality in practice and service provision by Australian pharmacists.

While professional practice resources are intended to be key in guiding pharmacy practice, this relies on them being used. Furthermore, use of practice guidance 
Box 1 Pharmaceutical Society of Australia (PSA) Professional Practice Guidance Resources included in survey by resource group

\begin{tabular}{|c|c|}
\hline Professional practice guidance resource grouping for survey & Professional practice guidance resources included \\
\hline $\begin{array}{l}\text { Resource Group 1-Overarching Practice Standards, Codes and Guide- } \\
\text { lines } \\
\text { (Referred to intext as 'Overarching Resources') }\end{array}$ & $\begin{array}{l}\text { My Health Record Guidelines for Pharmacists [29] } \\
\text { Clinical Governance Principles for Pharmacy Services [27] } \\
\text { Dispensing Practice Guidelines [3] } \\
\text { Code of Ethics for Pharmacists [2] } \\
\text { Professional Practice Standards for Pharmacists [1] } \\
\text { Guide to Providing Pharmacy Services to Aboriginal and Torres Strait } \\
\text { Islander People [23] }\end{array}$ \\
\hline $\begin{array}{l}\text { Resource Group 2-Community Pharmacy Core Professional Services } \\
\text { Practice Guidelines } \\
\text { (Referred to intext as 'Core Professional Service Resources') }\end{array}$ & $\begin{array}{l}\text { Guidelines for Pharmacists Providing Dose Administration Aid Services [26] } \\
\text { Guidelines for Pharmacists Providing Staged Supply Services [24] } \\
\text { Guidelines for Pharmacists Providing Medscheck and Diabetes Medscheck } \\
\text { Services [25] } \\
\text { Practice Guidelines for the Provision of Immunisation Services Within } \\
\text { Pharmacy [5] } \\
\text { Guidelines for the Continued Dispensing of Eligible Prescribed Medicines } \\
\text { by Pharmacists [28] }\end{array}$ \\
\hline $\begin{array}{l}\text { Resource Group 3-Accredited Medication Review Services Practice } \\
\text { Guidelines } \\
\text { (Referred to intext as 'Medication Review Resources') }\end{array}$ & $\begin{array}{l}\text { Guidelines for Quality Use of Medicines (QUM) Services [30] } \\
\text { Guidelines for Pharmacists Providing Home Medicines Review (HMR) } \\
\text { Services [21] } \\
\text { Guidelines for Pharmacists Providing Residential Medication Management } \\
\text { Review and QUM Services [22] } \\
\text { Guidelines for Comprehensive Medication Management Reviews [17] }\end{array}$ \\
\hline
\end{tabular}

resources is a professional behaviour in its own right, yet little is known about if and how professional practice resources are used by pharmacists. One previous qualitative study on the application of ethical principles by Australian pharmacists $(n=25)$ found that most participants did not look to the Code of Ethics for Pharmacists when faced with an ethical dilemma, but instead relied on their own knowledge and the principle of acting in 'the best interests of the patient' [7]. It was concluded that pharmacists found the Code of Ethics document was 'of little value in practice' [7]. Another qualitative study conducted over a decade ago found Australian pharmacists $(n=17)$ displayed a poor awareness and limited use of the PSA Practice Standards for Dispensing, citing its length and lack of identification of essential versus desirable actions as problematic [16]. The authors discovered a lack of integration of practice standards into practice processes and as such called for the useability and applicability of these documents to be reviewed to optimise integration to improve processes and patient care [16]. Since this study the Professional Practice Standards for Pharmacists have been reviewed and updated twice, however, internationally no further research exploring pharmacists' use of the standards, or any other related professional practice guidance resources has been identified [16].

Beyond the work of Hattingh et al. [16], no previous studies have investigated if and how pharmacists, interns or pharmacy students use professional practice resources more broadly. Without contemporary clarity as to the current usage patterns of professional practice resources, the ability for policymakers and developers to improve and tailor them to the needs of the profession is limited. Furthermore, understanding usage patterns may partly explain observed and reported inconsistencies in practice. Thus, the present study aimed to characterise Australian pharmacists' use of general professional practice guidance resources including nationally recognised Practice Guidelines [3, 5, 17, 21-30], Code of Ethics [2] and Professional Practice Standards for Pharmacists [1].

\section{Methods Study design}

A cross sectional, self-administered, electronic survey of pharmacists, intern pharmacists and pharmacy students living in Australia was conducted in July 2020. The survey considered professional practice resources essential to guiding general professional, ethical and legal practice when delivering pharmacy services and practising as a pharmacist. Only guidance resources that are freely accessible by pharmacists, intern pharmacists, and pharmacy students (including practice guidelines [3, 5, 17, 21-30], Code of Ethics [2] and Professional Practice Standards for Pharmacists [1]) were examined (Box 1). They are particularly relevant to pharmacists practising in a community setting, although not all guidance resources are directly relevant to every pharmacist's current scope of practice (e.g., they may not currently administer vaccinations; therefore, vaccination guidelines are not necessary).

This survey was conducted as part of a broader research project seeking to understand Australian 
pharmacists' information seeking behaviours and use of a wide range of professional practice guidance resources including: practice standards, codes of conduct, practice guidelines, medicines supply guidelines and the Australian Pharmaceutical Formulary and Handbook [31]. The professional practice guidance resources included in the full study were chosen in collaboration with the peak body representing Australian pharmacists, the Pharmaceutical Society of Australia (PSA). Findings relating to information seeking behaviour, use of medicines supply guidelines and the Australian Pharmaceutical Formulary and Handbook will be reported elsewhere.

The conduct and results of this study are reported according to the Checklist for Reporting Results of Internet E-Surveys (CHERRIES) checklist (Table 4 in Appendix) [32].

\section{Ethical approval}

Approval to conduct this study was granted by The University of Western Australia (UWA) Human Research Ethics Committee in June 2020 (RA/4/20/6014).

\section{Participants}

Pharmacists and intern pharmacists were eligible to participate if they held current registration with the Australian Health Practitioner Regulation Agency in Australia. Pharmacy students were eligible to participate if they were enrolled in a pharmacy degree course accredited by the Australian Pharmacy Council and currently studying in Australia.

\section{Sample size}

A minimum $1 \%$ quota sample of pharmacists, intern pharmacists and pharmacy students were prespecified and calculated using Pharmacy Board registration data that was current at the time [33]. The selection of $1 \%$ of the population was intended to be pragmatic and achievable in the absence of existing research to inform the selection of relevant outcomes to inform a sample size calculation. Furthermore, there was no reliable method for researchers to contact all pharmacists registered in Australia to recruit a systematic or randomised sample. At the time of designing this study, there were 32,777 registered Australian pharmacists, thus a minimum of 328 registered pharmacists were recruited. There were 1865 provisionally registered pharmacists in Australia; therefore, a minimum of 19 intern pharmacists were recruited. There were approximately 6500 pharmacy students in Australia; therefore, a minimum of 65 pharmacy students were recruited.

\section{Recruitment/distribution}

The survey was open from 7th July 2020 to 31st July 2020. All initial contact with participants was via the internet. A description of the study and Qualtrics ${ }^{\text {TM }}$ (Qualtrics, Provo, UT, Version July 2020 to September 2020) survey link and/or QR code was shared via professional organisations email lists (Pharmaceutical Society of Australia and Society of Hospital Pharmacists Australia), on social media (pharmacy related Facebook groups, Twitter, LinkedIn, pharmacy related Instagram pages) via advertisements in pharmacy related print and electronic media (Pharmacy Daily, Australian Journal of Pharmacy), through sharing of emails with intern training program providers, directors of pharmacy programs, pharmacy student associations, pharmacy banner groups, individual pharmacies and through the research team's professional networks. The advertisements encouraged participation and sharing of the opportunity to participate. The link directed participants to the full participant information landing page and consent to participate page prior to allowing them to complete the screening questions.

\section{Incentive to participate}

Upon completion of the survey participants could elect to enter a draw to win one of three $\$ 100$ retail vouchers. Details provided by the participants were collected using a separate Qualtrics survey link and could not be linked to the participant's responses.

\section{Survey design}

The survey was developed by the research team and reviewed by the Pharmaceutical Society of Australia (PSA) Projects team. Draft questions were piloted via the platform (Qualtrics ${ }^{\mathrm{TM}}$ ) for readability, content and platform useability by a convenience sample of pharmacists $(n=12)$, intern pharmacists $(n=4)$ and pharmacy students $(n=6)$ invited via the research teams' professional network. In response to pilot feedback minor changes were made to response options, display of the survey, and typographical errors were corrected.

\section{Final survey}

The full survey comprised a total 83 items including multiple-answer checkbox, ranking, multiple-choice, and free text response questions that considered the participants information seeking behaviour and use of professional practice guidance resources in the past 12 months. Questions pertaining to the current study (use of professional practice resources) broadly examined resource selection, frequency of use, reasons resources were selected (or not selected for use), how resources were used, perceived 
usefulness of resources, and key demographics. Adaptive questioning was enabled based on the participant's individual responses. Response items were randomised to reduce bias in responses. The professional practice resources examined in the current study were separated into three groups, namely, 'Overarching Resources', 'Core Professional Service Resources' and 'Medication Review Resources' (Box 1).

Mandatory response was enabled for all questions except the free text responses and multiple answer checkbox questions, where no selection indicated that none of the choices were appropriate. An 'I don't know' or 'I can't remember' response was available for questions, where it was deemed appropriate. The survey program prompted participants to complete mandatory questions prior to submitting that page. Participants could choose to go back through questions and change responses prior to submitting the final survey. The survey was an open survey available nationally using online survey software system, Qualtrics ${ }^{\mathrm{TM}}$. All responses were anonymous.

Participation in the survey was voluntary and consent to participate was indicated through response to a question at the beginning of the survey. All participants were made aware of the purpose of the study, time needed to complete the survey, data storage, investigators and funder through the participant information available at the beginning of the survey. Thus, providing informed consent.

The 'prevent ballot box stuffing' function was turned on in the Qualtrics ${ }^{\mathrm{TM}}$ program and enabled placement of a cookie on the access page for the survey link, preventing participants taking the survey multiple times. Qualtrics ${ }^{\mathrm{TM}}$ anonymise responses was enabled, so IP addresses were not recorded or checked. No log file analysis techniques were used. Qualtrics ${ }^{\mathrm{TM}}$ bot detection was enabled.

\section{Data analysis}

The data set was exported from Qualtrics ${ }^{\mathrm{TM}}$ to the latest version of Microsoft Excel. Responses that had the demographics section of the survey and the first content question answered/completed were eligible for inclusion for this analysis. This included partial responses. Responses that met this criterion but were detected with an atypical timestamp for completion (e.g., less than $3 \mathrm{~min}$, when it is estimated to take at least $5 \mathrm{~min}$ to get to the first content question) were reviewed to determine if the survey had been completed and presented as intended in the software.

Descriptive statistics including counts and proportions were calculated in STATA Software, Release 16 (StataCorp LLC, College Station, TX, USA). Unique site visitors could not be tracked in Qualtrics ${ }^{\mathrm{TM}}$; therefore, view rate and participation rate are not reported. No statistical correction was utilised in this analysis.

\section{Results}

After screening, $601 \quad(n=601 / 774,77.6 \%)$ responses met the minimum requirement for inclusion in the current analysis and are presented in this report. Of these, $462(n=462 / 601,76.9 \%)$ respondents were registered pharmacists, $88(n=88 / 601,14.6 \%)$ were pharmacy students and $51(n=51 / 601,8.5 \%)$ were intern pharmacists. Table 1 summarises the demographics of the survey respondents.

\section{Use of the professional practice resources}

The proportion of participants who used the selected professional practice guidance resources in the last 12 months by participant group is shown in Fig. 1. Further detail is provided in Table 2 . The most frequently used professional practice guidance resources in the past 12 months were the Australian Professional Practice Standards for Pharmacists, followed by the Dispensing Practice Guidelines and the Code of Ethics for Pharmacists (Table 2). A greater proportion of intern pharmacist and pharmacy students used these top three resources compared to registered pharmacists (Fig. 1). All guidance resources except the Australian Professional Practice Standards for Pharmacists had been used by less than $50 \%$ of all respondents (Fig. 1, Table 2). A smaller proportion of pharmacy student respondents had used the Core Professional Services Resources (Group 2) compared to registered pharmacists and interns (Fig. 1, Table 2).

All Medication Review Resources (Group 3) had been used by less than a quarter of participants in each respondent group. A greater proportion of pharmacy students and registered pharmacists had used each of these resources than intern pharmacists (Fig. 1, Table 2).

Table 3 shows the proportion of respondents' selected reasons for using the guidance resources, how respondents used the resources, perceived usefulness and reasons for not using professional practice resources by respondent group and resource group.

\section{Reasons for using selected professional practice resources}

The top three most common reasons for using selected professional practice guidance resources were for respondents to familiarise themselves with the contents, update their knowledge and to check their practice reflects best practice (Table 3). 
Table 1 Demographics of survey respondents

\begin{tabular}{|c|c|c|c|c|}
\hline Characteristic & $\begin{array}{l}\text { Registered } \\
\text { pharmacist } \\
(N=462)\end{array}$ & $\begin{array}{l}\text { Pharmacy intern } \\
(N=51)\end{array}$ & $\begin{array}{l}\text { Pharmacy student } \\
(N=88)\end{array}$ & $\begin{array}{l}\text { All } \\
(N=601)\end{array}$ \\
\hline \multicolumn{5}{|l|}{ Gender (n (\%)) } \\
\hline Male & $132(28.6)$ & $12(23.5)$ & $24(27.3)$ & $168(28.0)$ \\
\hline Female & $328(5.3)$ & $39(76.5)$ & $63(71.6)$ & $430(71.5)$ \\
\hline Non-conforming/gender variant & $0(0.0)$ & $0(0.0)$ & $0(0.0)$ & $0(0.0)$ \\
\hline Prefer not to answer & $2(0.4)$ & $0(0.0)$ & $1(1.1)$ & $3(0.5)$ \\
\hline \multicolumn{5}{|l|}{ Age (in years) ( $n(\%))$} \\
\hline $18-24$ & $18(3.9)$ & $39(76.5)$ & $70(79.5)$ & $127(21.1)$ \\
\hline $25-34$ & $215(46.5)$ & $10(19.6)$ & $12(13.6)$ & $237(39.4)$ \\
\hline $35-44$ & $101(21.9)$ & $1(2.0)$ & $4(4.5)$ & $106(17.6)$ \\
\hline $45-54$ & $61(13.2)$ & $1(2.0)$ & $1(1.1)$ & $63(10.5)$ \\
\hline $55-64$ & $47(10.2)$ & $0(0.0)$ & $0(0.0)$ & $47(7.8)$ \\
\hline $65+$ & $18(3.9)$ & $0(0.0)$ & $0(0.0)$ & $18(3.0)$ \\
\hline Prefer not to answer & $2(0.4)$ & $0(0.0)$ & $1(1.1)$ & $3(0.5)$ \\
\hline None of the above & $0(0.0)$ & $0(0.0)$ & $0(0.0)$ & $0(0.0)$ \\
\hline \multicolumn{5}{|l|}{ State of workplace/study ( $n(\%))$} \\
\hline New South Wales & 85 (18.4) & $6(11.8)$ & $13(14.8)$ & $104(17.3)$ \\
\hline Victoria & $118(25.5)$ & $9(17.6)$ & $19(21.6)$ & $146(24.3)$ \\
\hline Queensland & $54(11.7)$ & $11(21.6)$ & $19(21.6)$ & $84(14.0)$ \\
\hline South Australia & $46(10.0)$ & $10(19.6)$ & $12(13.6)$ & $68(11.3)$ \\
\hline Western Australia & $127(27.5)$ & $7(13.7)$ & $18(20.5)$ & $152(25.3)$ \\
\hline Northern Territory & $5(1.1)$ & $2(3.9)$ & $0(0.0)$ & $7(1.2)$ \\
\hline Australian Capital Territory & $10(2.2)$ & $3(5.9)$ & $3(3.4)$ & $16(2.7)$ \\
\hline Tasmania & $12(2.6)$ & $3(5.9)$ & $3(3.4)$ & $18(3.0)$ \\
\hline Prefer not to answer & $4(0.9)$ & $0(0.0)$ & $1(1.1)$ & $5(0.8)$ \\
\hline \multicolumn{5}{|l|}{ Currently member of any pharmacy organisations $(n(\%))^{*}$} \\
\hline Pharmaceutical Society of Australia & $233(50.4)$ & $34(66.7)$ & $80(90.9)$ & $347(57.7)$ \\
\hline Society of Hospital Pharmacists Australia & $126(27.3)$ & $15(29.4)$ & $54(61.4)$ & $195(32.4)$ \\
\hline Pharmacy Guild of Australia & $93(20.1)$ & $9(17.6)$ & $26(29.5)$ & $128(21.3)$ \\
\hline Professional Pharmacists Australia & 49 (10.6) & $6(11.7)$ & $4(4.5)$ & $59(9.8)$ \\
\hline National Australian Pharmacy Student Association (NAPSA) & $11(2.4)$ & $9(17.6)$ & $43(48.9)$ & $63(10.5)$ \\
\hline International Pharmaceutical Federation (FIP) & $12(2.6)$ & $3(5.9)$ & $2(2.3)$ & $17(2.8)$ \\
\hline None of the above $\#$ & $88(19.0)$ & $7(13.7)$ & $4(4.5)$ & $99(16.5)$ \\
\hline Prefer not to answer ${ }^{\#}$ & $5(1.1)$ & $0(0.0)$ & $0(0.0)$ & $5(0.8)$ \\
\hline Other & $43(9.3)$ & $1(2.0)$ & $2(2.3)$ & $46(7.7)$ \\
\hline \multicolumn{5}{|l|}{ Pharmacist principal role $(n(\%))$} \\
\hline Community pharmacy, owner & $48(10.4)$ & - & - & - \\
\hline Community pharmacy, employee & $209(45.2)$ & - & - & - \\
\hline Hospital pharmacy & $110(23.8)$ & - & - & - \\
\hline Academia & $25(5.4)$ & - & - & - \\
\hline Consultant & $33(7.14)$ & - & - & - \\
\hline Industry & $8(1.7)$ & - & - & - \\
\hline Prefer not to answer & $3(0.7)$ & - & - & - \\
\hline Other & $26(5.6)$ & - & - & - \\
\hline \multicolumn{5}{|l|}{ Intern pharmacist principal place of practice $(n(\%))$} \\
\hline Community Pharmacy & - & $30(58.8)$ & - & - \\
\hline Hospital Pharmacy & - & $19(37.3)$ & - & - \\
\hline Industry & - & $0(0.0)$ & - & - \\
\hline Prefer not to answer & - & $0(0.0)$ & - & - \\
\hline
\end{tabular}


Table 1 (continued)

\begin{tabular}{|c|c|c|c|c|}
\hline Characteristic & $\begin{array}{l}\text { Registered } \\
\text { pharmacist } \\
(N=462)\end{array}$ & $\begin{array}{l}\text { Pharmacy intern } \\
(N=51)\end{array}$ & $\begin{array}{l}\text { Pharmacy student } \\
(N=88)\end{array}$ & $\begin{array}{l}\text { All } \\
(N=601)\end{array}$ \\
\hline Other & - & $2(3.9)$ & - & - \\
\hline Pharmacist years registered (n (\%)) & & & - & - \\
\hline $0-2$ & $56(12.1)$ & - & - & - \\
\hline $3-5$ & $77(16.7)$ & - & - & - \\
\hline $6-10$ & $114(24.7)$ & - & - & - \\
\hline $11-20$ & $108(23.4)$ & - & - & - \\
\hline $21-30$ & $41(8.9)$ & - & - & - \\
\hline$>31$ & $66(14.3)$ & - & - & - \\
\hline \multicolumn{5}{|c|}{ Current medication management review accreditation ( $n(\%))$} \\
\hline Yes & $95(20.6)$ & - & - & - \\
\hline No & $366(79.2)$ & - & - & - \\
\hline Prefer not to answer & $1(0.2)$ & - & - & - \\
\hline \multicolumn{5}{|c|}{ How often have they worked as a sole pharmacist in the last 12 months $(n(\%))$} \\
\hline Never & $90(19.5)$ & - & - & - \\
\hline Rarely & $115(24.9)$ & - & - & - \\
\hline Sometimes & $60(13.0)$ & - & - & - \\
\hline Often & $86(18.6)$ & - & - & - \\
\hline Always & $103(22.3)$ & - & - & - \\
\hline Prefer not to answer & $8(1.7)$ & - & - & - \\
\hline \multicolumn{5}{|c|}{ Modified Monash Model Category for current practice location (n (\%)) } \\
\hline MM 1-Metropolitan & $320(69.3)$ & $32(62.8)$ & - & - \\
\hline MM 2-Regional & $41(8.9)$ & $6(11.7)$ & - & - \\
\hline MM 3-Large rural town & $29(6.3)$ & $4(7.8)$ & - & - \\
\hline MM 4-Medium rural town & $8(1.7)$ & $0(0.0)$ & - & - \\
\hline MM 5—Small rural town & $44(9.6)$ & $6(11.8)$ & - & - \\
\hline MM 6_Remote community & $7(1.5)$ & $2(3.9)$ & - & - \\
\hline MM 7-Very remote community & $9(2.0)$ & $1(2.0)$ & - & - \\
\hline Prefer not to answer & $4(0.9)$ & $0(0.0)$ & - & - \\
\hline
\end{tabular}

$N=$ total responses for that question and population, $\mathrm{n}=$ total responses for that answer, $\%=n / N \times 100 \%$

*A multiple answer question, percentages will not add up to 100

\# An exclusive answer

- Question was not asked of that respondent group

\section{How respondents used selected professional practice resources}

Most respondents only read part of the selected guidance resource. This was mostly consistent across respondent groups (Table 3 ).

\section{Perceived usefulness of selected professional practice resources}

Of those who had used at least one professional practice guidance resource most respondents found the resources 'very useful' (Table 3). Few respondents indicated the resources were 'not at all' useful (Table 3).

\section{Reasons for not using professional practice resources}

The most common reasons for not using the professional practice guidance resources were that the respondents did not need the information that the resource contained, the respondents did not know the resource existed or respondents did not considering the resources relevant to their practice area (Table 3). Less than a quarter of respondents indicated that they had used these resources in the past but not in the last 12 months (Table 3). 


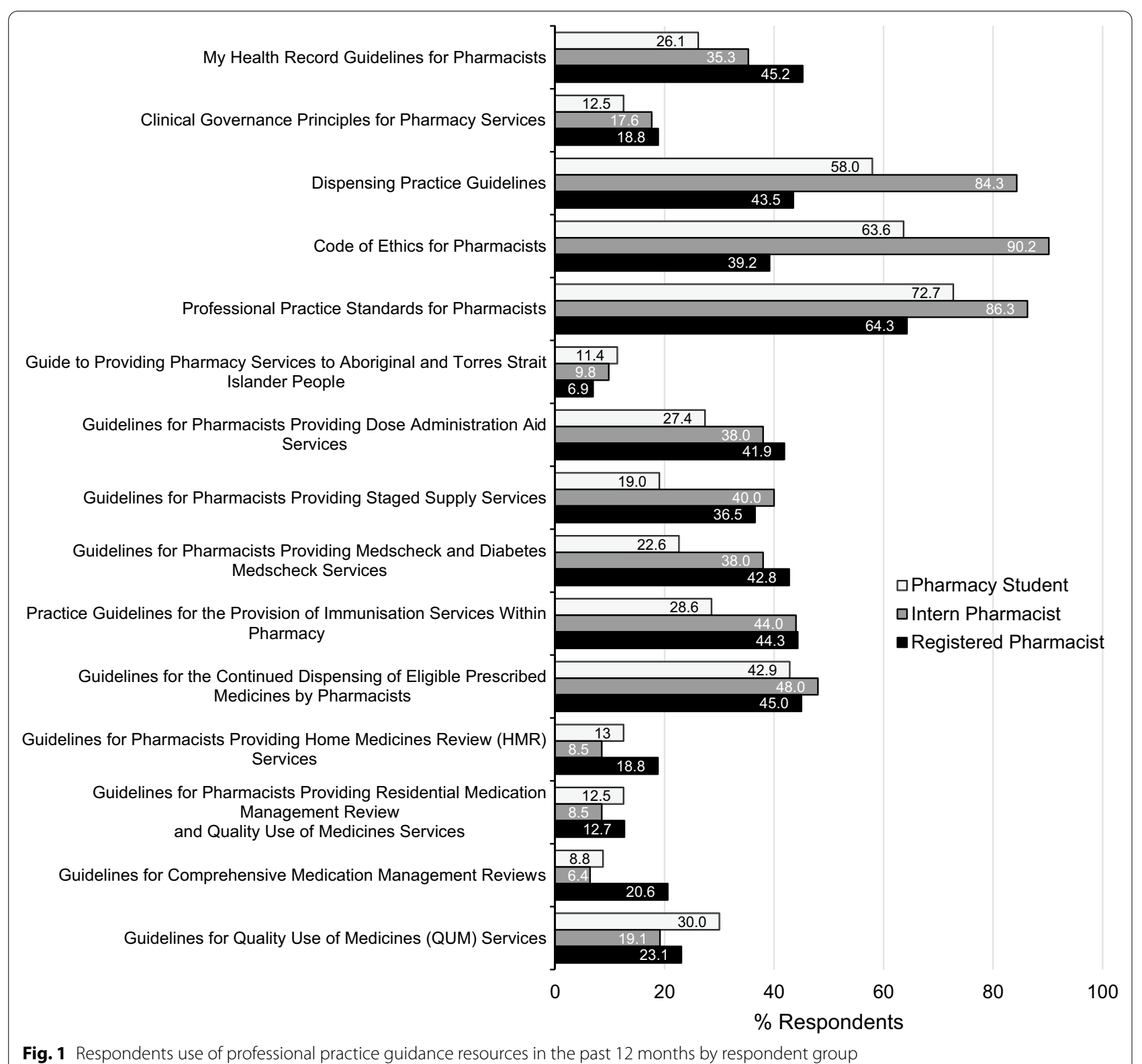

Fig. 1 Respondents use of professional practice guidance resources in the past 12 months by respondent group

\section{Discussion}

The current study is the first to investigate if and how pharmacy students, intern pharmacists and registered pharmacists use professional practice guidance resources. All professional practice resources investigated, except the Professional Practice Standards, had been used by less than half of all respondents in the preceding 12 months. The results show differences in use between pharmacy student, intern pharmacist and registered pharmacists' and suggest some resources may be more relevant to those learning (students and interns) compared to those practising (interns and registered pharmacists). These usage patterns may help to interpret inconsistencies in practice and can inform the tailoring of professional practice resources for future use.

To the researcher's knowledge this is the first-time changing use of practice guidance resources across pharmacist career stages has been described in the literature. The findings of this study suggest pharmacy students and interns used Overarching Resources that relate to essential components of pharmacy practice more often than pharmacists. These results are not surprising as students and interns need to understand 
Table 2 Respondents use of professional practice guidance resources in the last 12 months by respondent group

\begin{tabular}{|c|c|c|c|c|c|c|c|c|c|}
\hline \multirow{3}{*}{$\begin{array}{l}\text { Professional practice guidance resource } \\
\text { Resource Group 1-Overarching Practice Standards, Codes and Guidelines }\end{array}$} & \multirow{2}{*}{\multicolumn{2}{|c|}{$\begin{array}{l}\begin{array}{l}\text { Registered } \\
\text { Pharmacist }\end{array} \\
N=462\end{array}$}} & \multirow{2}{*}{\multicolumn{2}{|c|}{$\begin{array}{l}\text { Pharmacy } \\
\text { intern }\end{array}$}} & \multirow{2}{*}{\multicolumn{2}{|c|}{$\begin{array}{l}\text { Pharmacy } \\
\text { student } \\
N=88\end{array}$}} & \multicolumn{3}{|c|}{ All Respondents } \\
\hline & & & & & & & \multicolumn{3}{|c|}{$N=601$} \\
\hline & $n$ & $\%$ & $n$ & $\%$ & $n$ & $\%$ & $n$ & $\%$ & \\
\hline My Health Record Guidelines for Pharmacists & 209 & 45.2 & 18 & 35.3 & 23 & 26.1 & 250 & 41.6 & \\
\hline Clinical Governance Principles for Pharmacy Services & 87, & 18.8 & 9, & 17.6 & 11 & 12.5 & 107, & 17.8 & \\
\hline Dispensing Practice Guidelines & 201 & 43.5 & 43 & 84.3 & 51 & 58.0 & 295, & & \\
\hline Code of Ethics for Pharmacists & 181, & 39.2 & 46, & 90.2 & 56 & 63.6 & 283 & 47.1 & \\
\hline Professional Practice Standards for Pharmacists & 297, & 64.3 & 44 & 86.3 & 64 & 72.7 & 405, & 67.4 & \\
\hline Guide to Providing Pharmacy Services to Aboriginal and Torres Strait Islander People & 32 & 6.9 & 5 & 9.8 & 10, & 11.4 & 47, & 7.8 & \\
\hline \multirow{2}{*}{\multicolumn{2}{|c|}{$\begin{array}{l}\text { Resource Group 2-Community Pharmacy Core Professional Services Practice } \\
\text { Guidelines }\end{array}$}} & \multicolumn{2}{|c|}{$N=317$} & \multicolumn{2}{|c|}{$N=36$} & \multicolumn{2}{|c|}{$N=49$} & \multicolumn{2}{|c|}{$N=402$} \\
\hline & & $n$ & $\%$ & $n$ & $\%$ & $n$ & $\%$ & $n$ & $\%$ \\
\hline Guidelines for Pharmacists Providing Dose Administration Aid Services & & 188 & 41.9 & 19 & 38 & 23 & 27.4 & 230 & 39.5 \\
\hline Guidelines for Pharmacists Providing Staged Supply Services & & 164 & 36.5 & 20, & 40 & 16, & 19.0 & 200 & 34.3 \\
\hline Guidelines for Pharmacists Providing Medscheck and Diabetes Medscheck Services & & 192 & 42.8 & 19 & 38 & 19, & 22.6 & 230, & 39.5 \\
\hline Practice Guidelines for the Provision of Immunisation Services Within Pharmacy & & 199, & 44.3 & 22 & 44 & 24 & 28.6 & 245 & 42.0 \\
\hline Guidelines for the Continued Dispensing of Eligible Prescribed Medicines by Pharmaci & & 202 & 45.0 & 24 & 48 & 36, & 42.9 & 262 & 44.9 \\
\hline \multirow{2}{*}{\multicolumn{2}{|c|}{ Resource Group 3-Accredited Medication Review Services Practice Guidelines }} & \multicolumn{2}{|c|}{$N=317$} & \multicolumn{2}{|c|}{$N=36$} & \multicolumn{2}{|c|}{$N=49$} & \multicolumn{2}{|c|}{$N=402$} \\
\hline & & $n$ & $\%$ & $n$ & $\%$ & $n$ & $\%$ & $n$ & $\%$ \\
\hline \multicolumn{2}{|l|}{ Guidelines for Quality Use of Medicines (QUM) Services } & 102 & 23.1 & 9, & 19.1 & 24 & 30.0 & 135, & 23.7 \\
\hline \multicolumn{2}{|l|}{ Guidelines for Pharmacists Providing Home Medicines Review (HMR) Services } & 83 & 18.8 & 4 & 8.5 & 10, & 13 & 97, & 17.0 \\
\hline \multicolumn{2}{|l|}{$\begin{array}{l}\text { Guidelines for Pharmacists Providing Residential Medication Management Review and QUM } \\
\text { Services }\end{array}$} & 56 & 12.7 & 4 & 8.5 & 10, & 12.5 & 70 & 12.3 \\
\hline \multicolumn{2}{|l|}{ Guidelines for Comprehensive Medication Management Reviews } & 91, & 20.6 & 3, & 6.4 & 7, & 8.8 & 101, & 17.8 \\
\hline
\end{tabular}

$N=$ total responses for that question and population

$n=$ total responses for that answer, e.g., yes I have used this resource in the past 12 months

$\%=n / N \times 100 \%$

QUM Quality Use of Medicines

the principles of being a pharmacist in preparation for provisional registration at the end of their degree. Interestingly students were also more likely to say that these resources were only somewhat useful compared to interns and pharmacists. The reasons identified for using professional practice resources was generally consistent across resource and respondent groups. Identified reasons for use included improving familiarity with the resource, updating knowledge, and checking practice. In contrast, variability for reasons for not using the resources were identified between respondent groups. Students and interns more often indicated that they did not know the resource existed compared to pharmacists. All groups indicated to varying degrees they did not need the resources that they had not used or that the practice resource was not relevant to their practice. This observed variability suggests that non-use may be resource dependent or driven by the current role, scope of practice and experience of the respondent.
Limited existing literature on the use of professional practice guidance resources in health professions, and in particular pharmacy, means that limited comparisons can be made with the current study's findings. Chaar et al. [7] explored the application of ethical principles and use of the Code of Ethics for Australian pharmacists. Hattingh et al. [16] investigated Australian pharmacists' use of the Practice Standards for Dispensing. Both reported that these resources do not appear to be used by most pharmacists in daily practice. The results of the current the current study are consistent with this. In particular, in the current study only $43.5 \%$ of pharmacists reported using the dispensing practice guideline in the previous 12 months, aligning with Hattingh et al.s finding that the majority of pharmacists did not know about or use the dispensing practice standard to develop their procedures [16]. This lack of awareness and our observed lack of use may explain, at least in part, why the majority of 


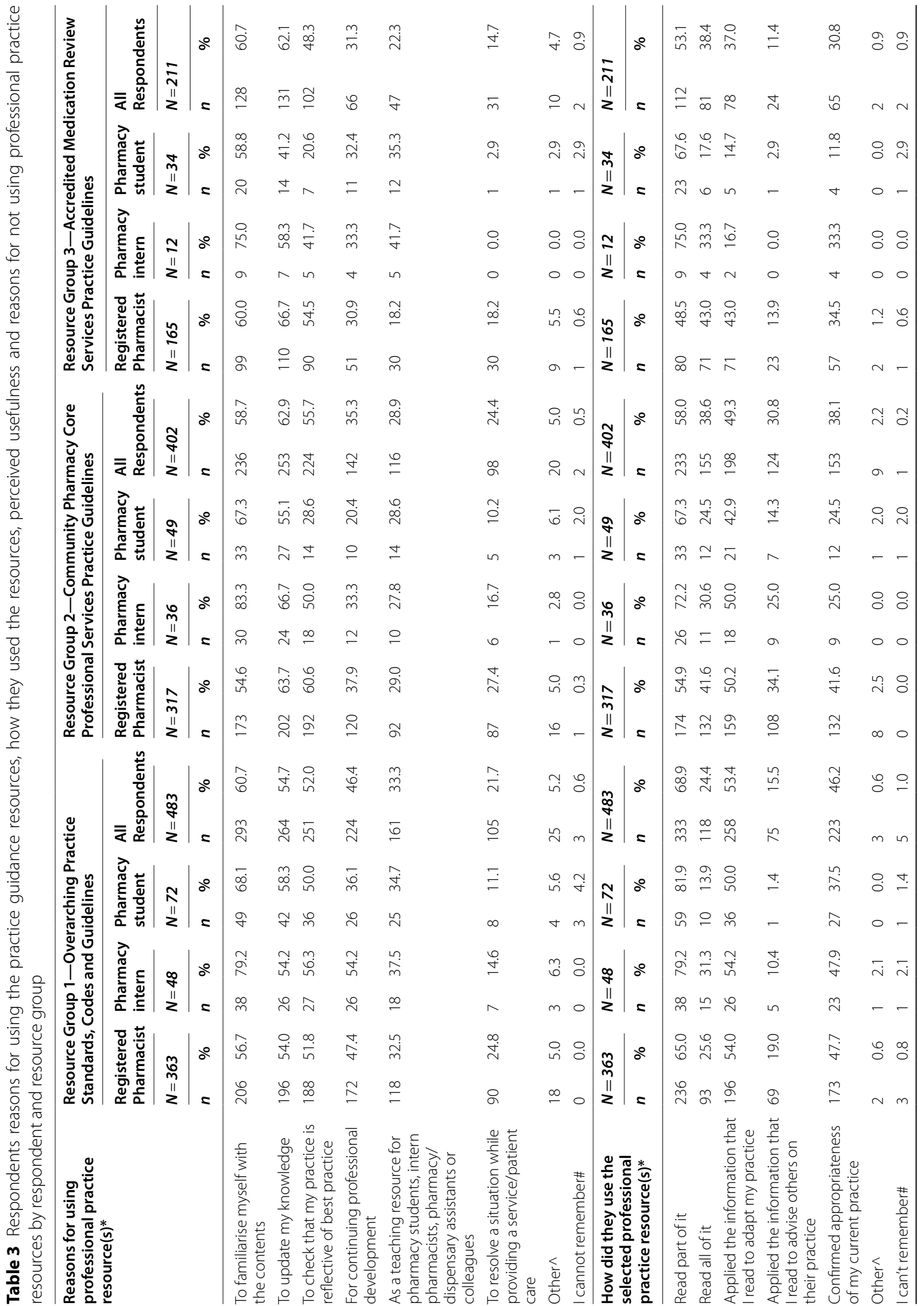


Mill et al. Journal of Pharmaceutical Policy and Practice $\quad$ (2021) 14:114

Page 11 of 19

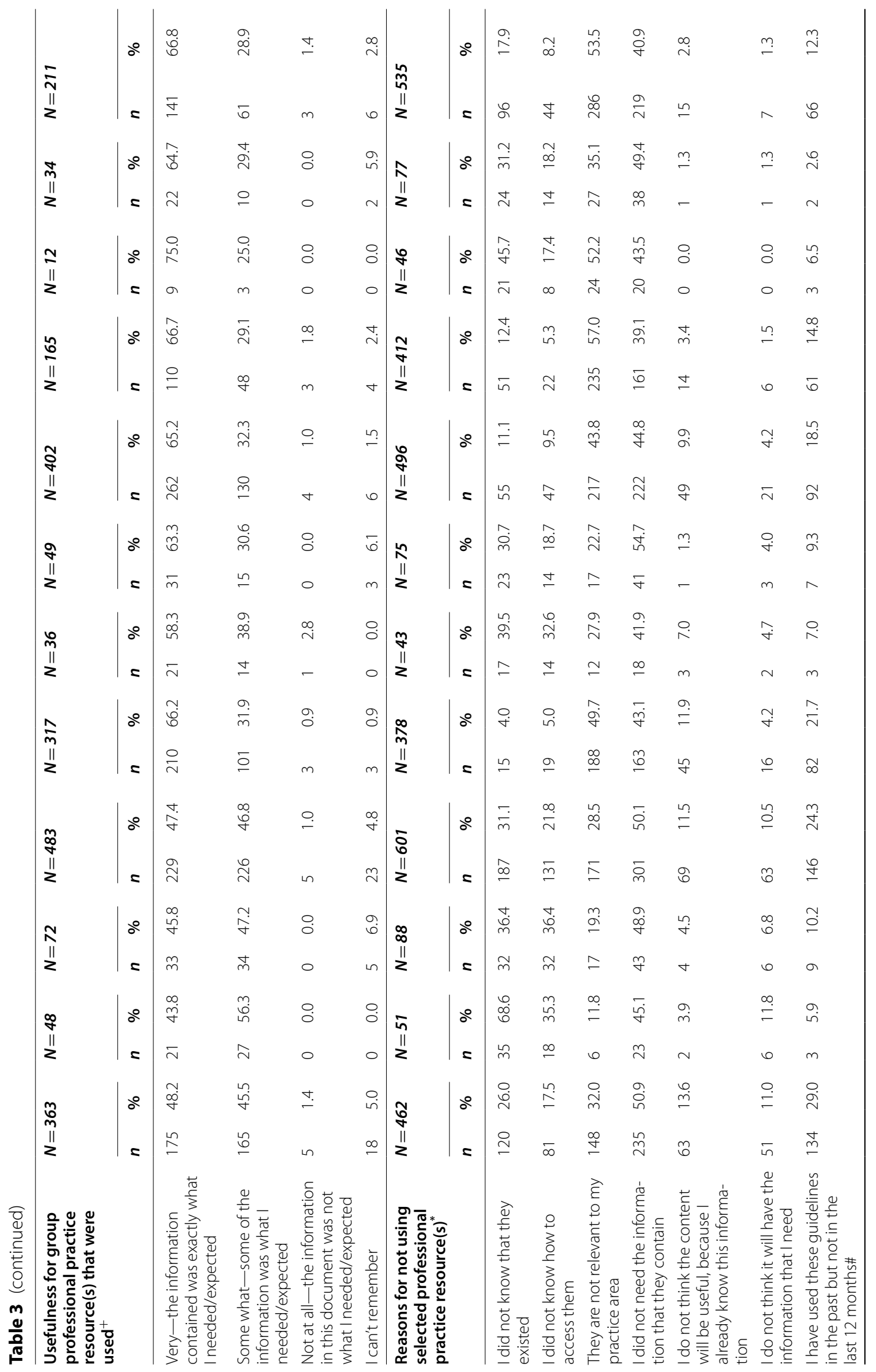




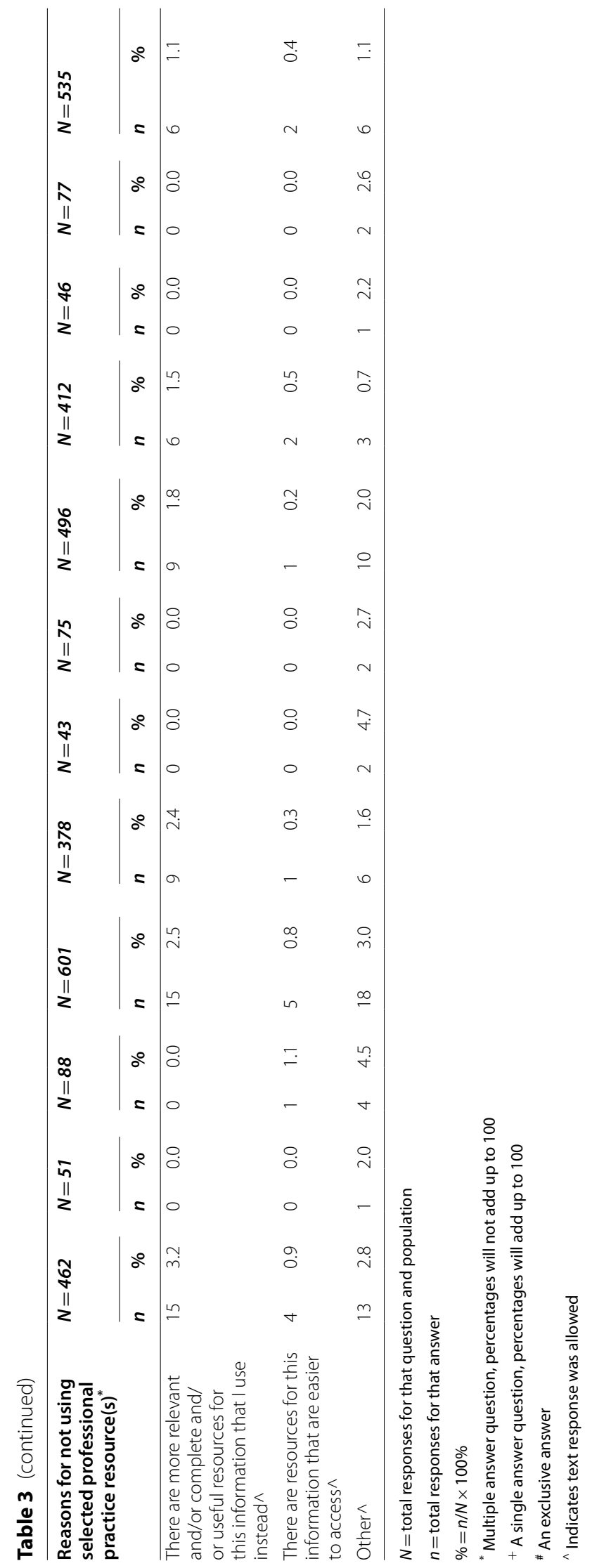


professional transgressions observed in disciplinary hearings related to dispensing processes [6]. Work by Nash et al. [34] on the use of National Competency Standards Framework for Pharmacists by Australian pharmacy students and pharmacists, found there is no accepted measure of what amount of practice resource use is associated with or necessary for quality practice. Given it is a condition of registration each year that pharmacists review the competency standards to identify areas, where they may need targeted professional development, it is alarming that Nash et al. [34] found not all pharmacists in their study had done this. No such requirement exists for the frequency of review for the professional practice resources examined in this study, and opinions on acceptable frequency of use are likely to differ across the profession. However, it would seem reasonable that these practice guidance resources are reviewed at least annually when pharmacists are renewing their registration and planning professional development to ensure they are aware of the content and any updates or changes.

\section{Implications for practice}

Where quality professional service provision and resultant renumeration are dependent on following guidelines, it would seem prudent that the pharmacist is always fully aware of the content of professional practice guidance resources. Continual review by practising pharmacists may be necessary to ensure that they are aware of how to provide acceptable patient care and avoid professional transgressions. Furthermore, if these resources are used during practice and provision of patient care they need to be accessed and read quickly, which has implications for the layout, host platforms and navigation functionalities. If registered pharmacists are only prompted to access guidelines when needing information for providing a service or care that they are unfamiliar with, this may limit their ability to keep up to date if guidance changes in between these prompts. For example, vaccination guidelines are continually changing throughout the national roll out in response to the COVID-19 pandemic and if pharmacists had only reviewed the guidelines at the start of the roll out, they may provide a service that does not meet guidelines. While the use of these resources has not been directly linked to pharmacist performance in providing these services, complying with them is correlated with maintaining registration in the case of the Code of Ethics and Professional Practice Standards [1, 2]. Compliance is also mandated for renumeration for some services (e.g., dose administration aid supply and home medicines review) [17, 26] and adherence to all resources is required to meet legal, ethical and professional practice expectations. Practicing in accordance with all resources closely would ensure a degree of consistency in service provision which serves to maintain trust in the profession from the people it serves $[35,36]$.

\section{Recommendations for practice}

As usage patterns for professional practice guidance resources differ throughout training to registration, resource developers should consider if these resources need to be tailored to the audience most likely to use them. This could be achieved through in-depth consultation with key stakeholders on what influences their behaviour. A richer understanding of influences for individual groups and resources could facilitate co-design and review of the resources. Professional practice resources need to be adequately detailed for pharmacist interns and for pharmacy students. They need to be easy to locate and navigate for practising pharmacists seeking information to provide immediate patient care. This balance may be hard to strike in a single document; however, with current technology, platforms for hosting professional practice resources could be adaptable and use display logic, diagrams, search functions and hyperlinks to account for this. Issues with awareness of the existence of the resources were also raised and suggest professional practice resource developers should revise how resources are shared and disseminated to the profession and students. The results of this study can directly help to guide the review process for the resources studied and may also be useful for guiding review of pharmacist professional practice resources internationally. Furthermore, these findings may also be useful to other health professions when considering review of their own professional resources.

\section{Strengths/limitations}

This study is the first to explore if and how pharmacists use a large range of professional practice guidance resources. This is one of the largest surveys to be completed involving Australian pharmacy students, interns and pharmacists and offers valuable insights into their usage patterns of professional practice resources. However, given this was a cross sectional survey, a number of limitations may have affected the generalisability of the results. First, common to all survey methodology completion of the study may be subject to respondent bias, where only motivated eligible participants respond. Thus, the results may 
have been influenced by limited responses from disengaged practitioners. We attempted to address that through a multi-faceted recruitment and distribution strategy; however, participation remained voluntary. It is possible that the results were skewed by voluntary participation, though it is likely that the findings reported here are more conservative findings compared to if disengaged practitioners had responded. The researchers extensively advertised the survey on a range of different platforms. This led to over $1 \%$ of each population completing the survey and a largely representative pharmacist sample when compared to national registration statistics. The participants seem to broadly represent those of the profession when compared to previous studies and current Australian Pharmacy Board data specifically for demographic characteristics, such as age and gender, and practice location [33, 37]. Differences of note are that the proportion of registered pharmacists' participants in Western Australia were higher and New South Wales were lower than those of the reported population. Demographic characteristics broadly reflect the profession though do not reflect professional engagement and motivation. The results may also be subject to retrospective recall bias. However, participants did have the option to select 'I cannot remember' if this was the case and its reasonable to assume that if they do not remember using the resource they probably did not. Furthermore, the self-reported use of a guideline was not compared to an objective assessment on whether it was required so no conclusions can be reached as to appropriateness of the frequency of reported use. This study was conducted during the height of Australia's second COVID-19 pandemic wave, when pharmacists were under considerable stress and regulations and guidelines for services were changing rapidly. How this may have affected the results is unknown. The present study shows a snapshot of use over 12 months by the respondents limiting understanding of what 'lifetime' use may be.

\section{Recommendations for future research}

The notion behind respondents expressing they did not 'need' particular guidance resources would be interesting to explore further. If it is that respondents assume they know the information, how do they know this knowledge is up to date? Does this assumption align with the resource developers' expectations? Does the pharmacist's knowledge translate to their practice? If resources users perceive the information to be irrelevant, how could it be improved for future use? To address this future work should set out to elicit a deeper understanding of why these resource use patterns were observed and what influences this professional behaviour. Qualitative methods may be particularly helpful here. This information could serve to inform redesign of the resources or behavioural interventions to enhance their usability.

\section{Conclusions}

Australian pharmacy students, intern pharmacists and registered pharmacists use of professional practice guidance resources varies. Core overarching resources are mostly used by pharmacy students and intern pharmacists compared to practising pharmacists, whereas interns and practising pharmacists are more likely, than pharmacy students to use guidelines that pertain to services that they are involved in providing (e.g., dose administration aids). Common reasons for using professional practice guidance resources included for familiarisation with the content, to seek information, and to check and support best practice. However, limited awareness of the existence of some resources and a lack of perceived relevance to individual practice were the most identified reasons for not using professional practice resources. This may pose a risk for individuals failing to meet professional obligations and result in professional transgressions that negatively impact patient experience or care. These results suggest that professional practice guidance resources need to be adequately detailed for new pharmacists and those studying, and easily accessed and navigated for practising pharmacists seeking information to provide immediate patient care. The results of this study are, therefore, invaluable to professional bodies responsible for developing these resources, who should consult key stakeholder groups (e.g., pharmacy students, intern pharmacists and registered pharmacists) in the resource design process. A richer understanding of what influences the use of professional practice resources could support the development of tailored interventions to increase professional behaviour across different groups and contexts and assist individuals to meet professional obligations.

\section{Appendix}

See Table 4. 


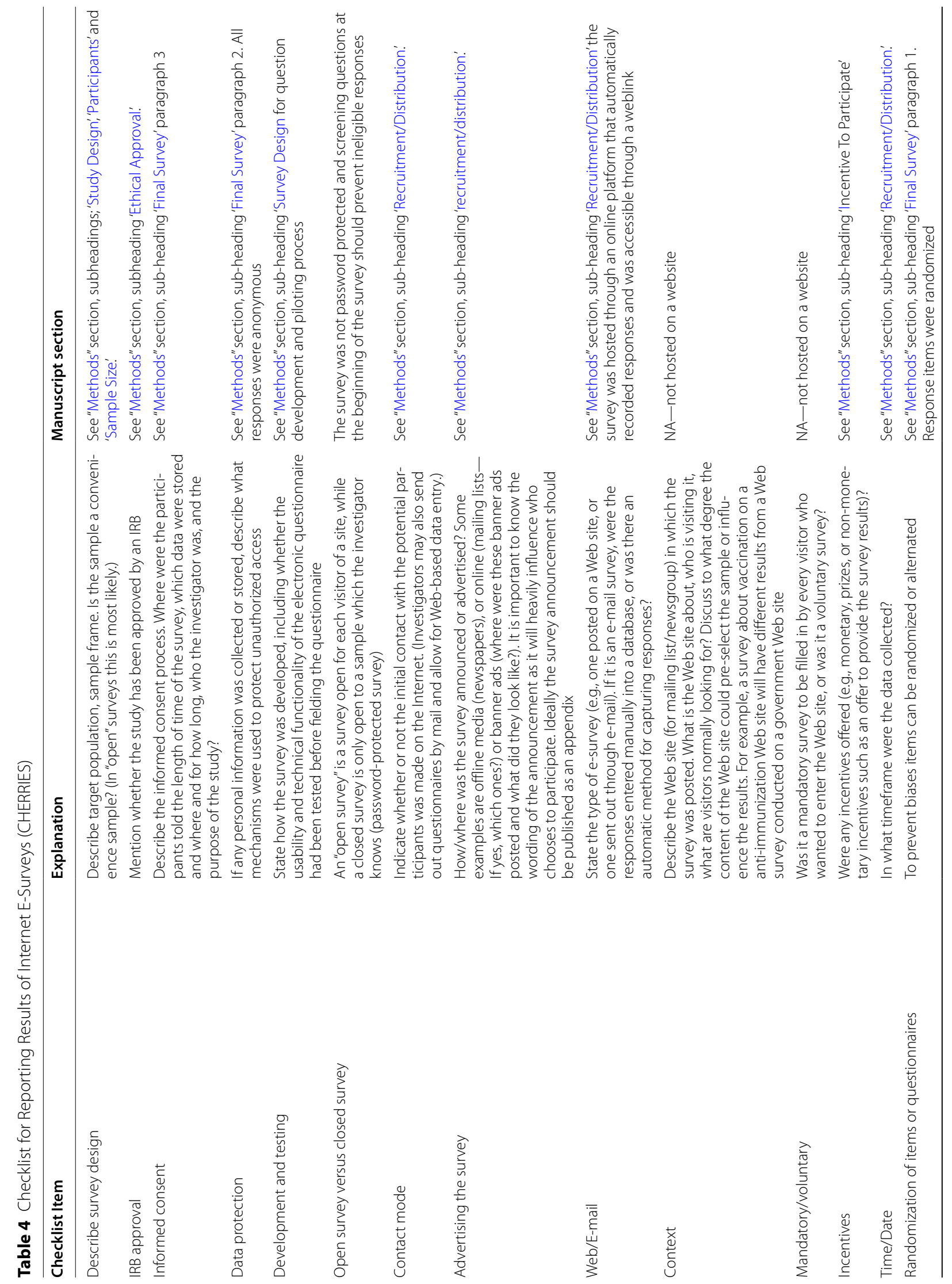



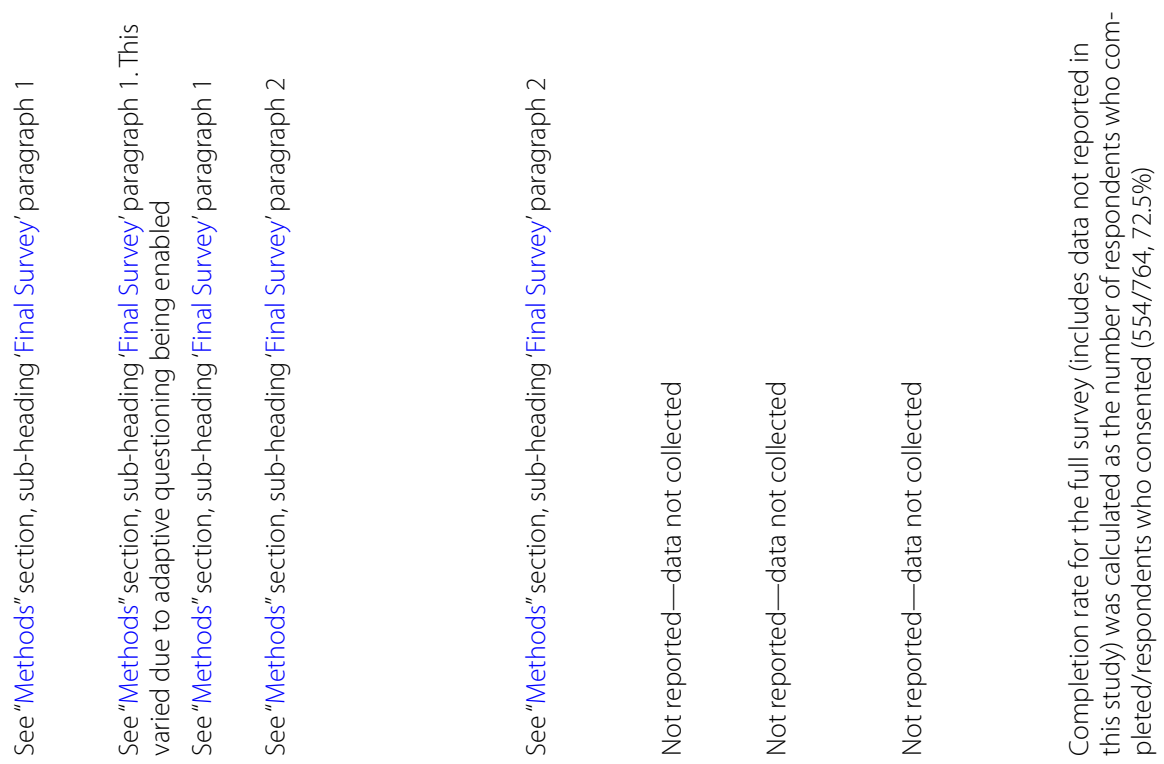

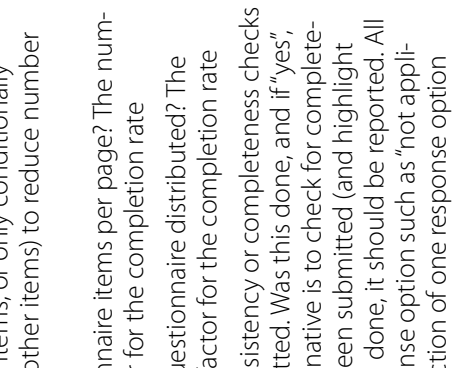

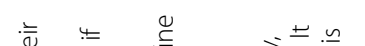

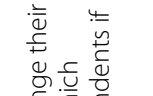

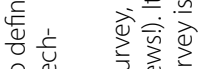

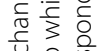

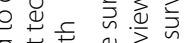

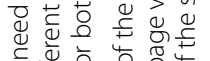

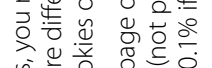

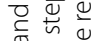

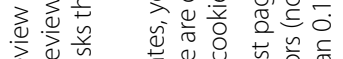

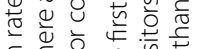

두일

을.

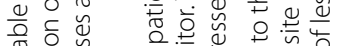

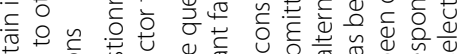

\& 考

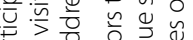

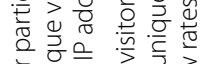

3 这

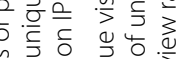

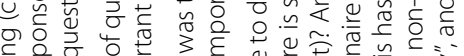

苋苾

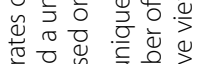

\begin{tabular}{|c|}
\hline 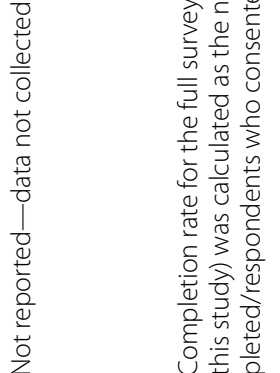 \\
\hline
\end{tabular}

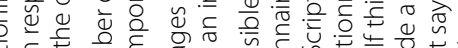

年

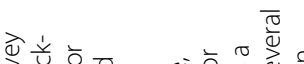

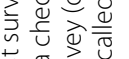

蒫它至品

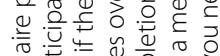

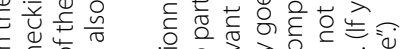

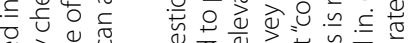

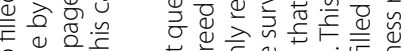

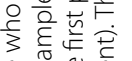

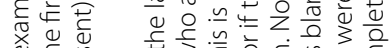

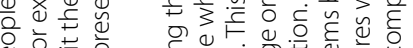

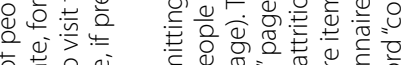

다워

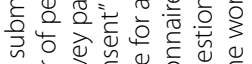

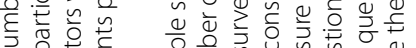

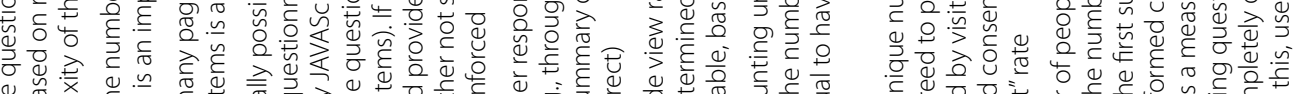

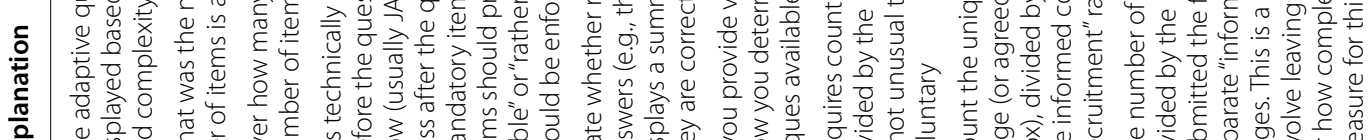

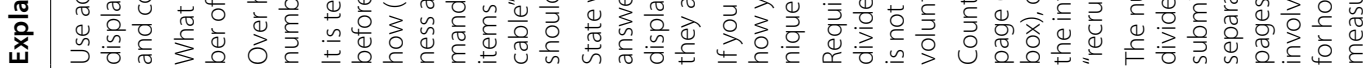
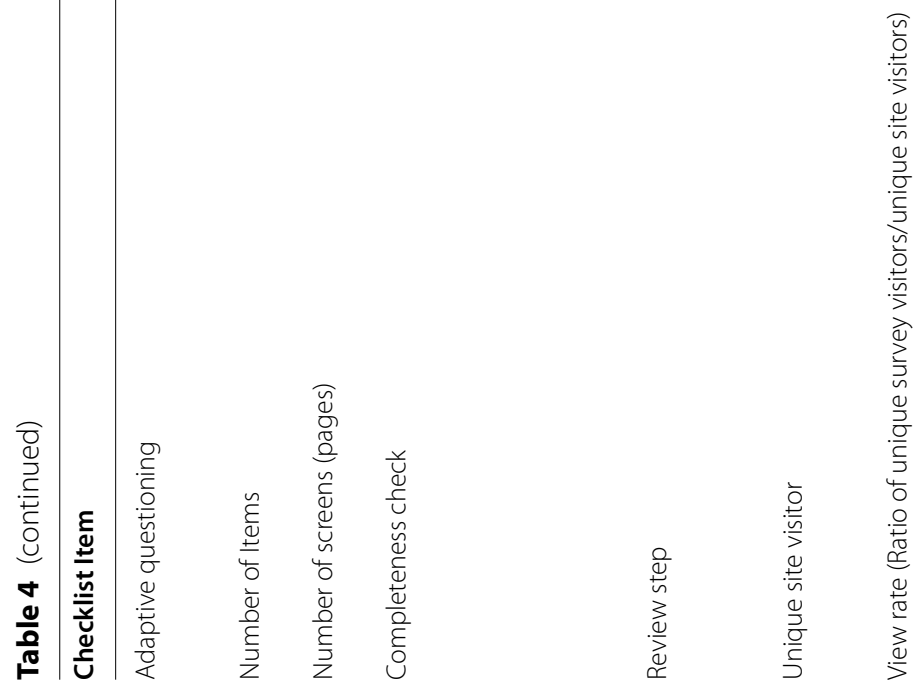

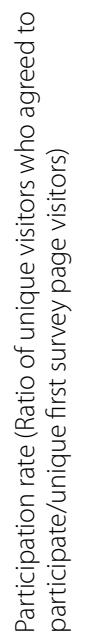

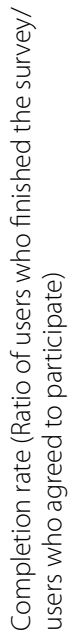




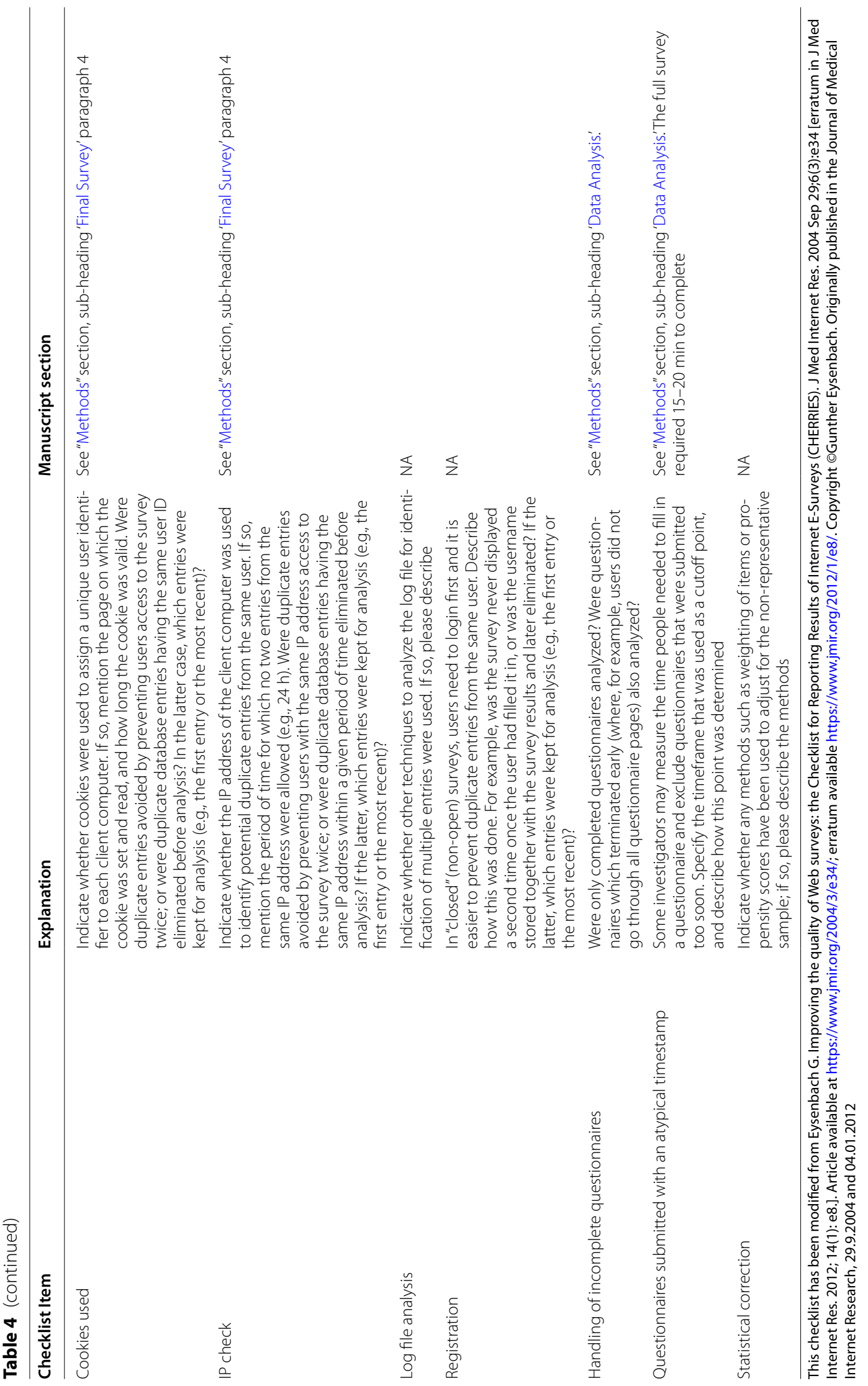




\author{
Abbreviation \\ PSA: Pharmaceutical Society of Australia.
}

\section{Acknowledgements}

The authors would like to thank all pharmacy students, intern pharmacists and pharmacists who piloted and completed the survey. The authors also thank members of the Pharmaceutical Society of Australia's project team and the Enhancing Quality in Pharmacy Practice (EQiPP) project expert advisory group for their input into recruitment strategies and survey development. DM is supported by an Australian Government Research Training Program Scholarship at The University of Western Australia. AP is supported by an NHMRC Early Career Fellowship (Grant No. 1156892).

\section{Authors' contributions}

DM: conceptualization, data curation, formal analysis, funding acquisition, investigation; methodology, project administration, resources, visualization, writing —original draft, writing — review and editing. JLJ: conceptualization, funding acquisition, investigation, methodology, supervision, writingreview and editing. KL: conceptualization, funding acquisition, methodology, supervision, writing - review and editing. SMS: conceptualization, funding acquisition, methodology, supervision, writing - review and editing. DD: conceptualization, methodology, supervision, writing—review and editing. LS: conceptualization, writing - review and editing. RC: conceptualization, funding acquisition, methodology, supervision, writing — original draft, writing review and editing. AP: conceptualization, formal analysis, funding acquisition, methodology, resources, software, writing - review and editing. All authors read and approved the final manuscript.

\section{Funding}

This study was partially funded by the Pharmaceutical Society of Australia.

\section{Availability of data and materials}

The data sets used and/or analysed during the current study may be available from the corresponding author conditionally in line with appropriate ethical approval.

\section{Declarations}

\section{Ethics approval and consent to participate}

Ethics approval has been received from UWA HREC: RA/4/20/6014.

\section{Consent for publication}

Not applicable.

\section{Competing interests}

At the time of writing this manuscript Deanna Mill was appointed as a Board Director for the Pharmaceutical Society of Australia.

\section{Author details}

${ }^{1}$ School of Allied Health, The University of Western Australia, Perth, WA, Australia. ${ }^{2}$ UniSA Clinical and Health Sciences, University of South Australia, Adelaide, SA, Australia. ${ }^{3}$ SA Pharmacy, SA Health, Adelaide, SA, Australia. ${ }^{4}$ Centre for Behaviour Change, Department of Clinical, Educational and Health Psychology, University College London, London, UK. ${ }^{5}$ Pharmacy Department, The Alfred, Melbourne, VIC, Australia. ${ }^{6}$ Centre for Medicines Use and Safety, Monash University, Melbourne, VIC, Australia.

Received: 25 October 2021 Accepted: 15 December 2021

Published online: 29 December 2021

\section{References}

1. Pharmaceutical Society of Australia. Professional Practice Standards-Version 5. 2017. Accessed Oct 12021

2. Pharmaceutical Society of Australia. Code of Ethics for Pharmacists. 2017. https://www.psa.org.au/wp-content/uploads/2018/07/PSA-Code-of-Ethics-2017.pdf. Accessed Oct 12021
3. Pharmaceutical Society of Australia. Dispensing Practice Guidelines. 2019. https://my.psa.org.au/s/article/Dispensing-Practice-Guidelines. Accessed Oct 12021

4. Pharmacy Board of Australia. Code of Conduct for Pharmacists. 2014. https://www.pharmacyboard.gov.au/codes-guidelines/code-of-conduct. aspx. Accessed Oct 12021

5. Pharmaceutical Society of Australia. Practice guidelines for the provision of immunisation services within pharmacy. 2020. https://my.psa.org.au/s/ article/immunisation-guidelines. Accessed Oct 12021

6. Penm J, Chaar BB. Professional transgressions by Australian pharmacists. J Pharm Pract Res. 2009;39(3):192-7.

7. Chaar B, Brien JA, Krass I. Professional ethics in pharmacy: The Australian experience. Int J Pharm Pract. 2005;13(3):195-204.

8. Jackson J, Urick B. Performance-based pharmacy payment models: the case for change. Aust Health Rev. 2019;43(5):502-7.

9. Smith H, Whyte S, Chan H, Kyle G, Lau E, Nissen L, et al. Pharmacist compliance with therapeutic guidelines on diagnosis and treatment provision. JAMA Netw Open. 2019;2(7):03.

10. Collins JC, Schneider CR, Moles RJ. Emergency contraception supply in Australian pharmacies after the introduction of ulipristal acetate: a mystery shopping mixed-methods study. Contraception. 2018;98(3):243-6.

11. Benrimoj SI, Gilbert AL, de Almeida Neto AC, Kelly F. National implementation of standards of practice for non-prescription medicines in Australia. Pharm World Sci. 2009;31(2):230-7.

12. Benrimoj SI, Werner JB, Raffaele C, Roberts AS. A system for monitoring quality standards in the provision of non-prescription medicines from Australian community pharmacies. Pharm World Sci. 2008;30(2):147-53.

13. Schneider C, Emery L, Brostek R, Clifford R. Evaluation of the supply of antifungal medication for the treatment of vaginal thrush in the community pharmacy setting: a randomized controlled trial. Pharm Pract. 2013:11(3):132-7.

14. Schneider C, Everett A, Geelhoed E, Kendall P, Murray K, Garnett P, et al. Provision of primary care to patients with chronic cough in the community pharmacy setting. Ann Pharmacother. 2011;45(3):402-8.

15. Higgins $\mathrm{SJ}, \mathrm{HI} \mathrm{H}$. Requests for emergency contraception in community pharmacy: an evaluation of services provided to mystery patients. Res Soc Adm Pharm. 2013;9(1):114-9.

16. Hattingh $\mathrm{HL}$, King MA, Smith NA. An evaluation of the integration of standards and guidelines in community pharmacy practices. Pharm World Sci. 2009;31(5):542-9.

17. Pharmaceutical Society of Australia. Guidelines for comprehensive medication management reviews. 2020. https://my.psa.org.au/s/article/guide lines-for-comprehensive-mmr. Accessed Oct 12021

18. International Pharmaceutical Federation. FIP Statement of Professional Standards- Code of ethics for pharmacists. 2014. www.fip.org/statements. Accessed July 72021

19. International Pharmaceutical Federation. Good Pharmacy Practice- Joint FIP/WHO Guidelines on GPP: Standards for quality of pharmacy services. 2011. https://www.fip.org/file/1476. Accessed July 72021

20. Pharmaceutical Society of Australia. National Competency Standards Framework for Pharmacists in Australia (2016). Internet. Deakin West, ACT, Australia 2016.

21. Pharmaceutical Society of Australia. Guidelines for pharmacists providing Home Medicines Review (HMR) services. 2011. https://www.ppaonline. com.au/wp-content/uploads/2019/01/PSA-Guidelines-for-ProvidingHome-Medicines-Review-HMR-Services.pdf. Accessed Oct 12021

22. Pharmaceutical Society of Australia. Guidelines for pharmacists providing Residential Medication Management Review (RMMR) and Quality Use of Medicines (QUM) services 2011 (Updated 2018). https://www.ppaonline. com.au/wp-content/uploads/2019/01/PSA-RMMR-and-QUM-Guidelines. pdf. Accessed Oct 12021

23. Pharmaceutical Society of Australia. Guide to providing pharmacy services to Aboriginal and Torres Strait Islander people. 2014. https://my. psa.org.au/s/article/Providing-Pharmacy-Services-to-Aboriginal-and-Torres-Strait-Islander-People. Accessed Oct 12021

24. Pharmaceutical Society of Australia. Guidelines for pharmacists providing staged supply services 2017 (Updated 2019). https://my.psa.org.au/servl et/fileField?entityld=ka10o0000001DaSAAU\&field=PDF_File_Member_ Content_Body_s. Accessed Oct 12021

25. Pharmaceutical Society of Australia. Guidelines for pharmacists providing MedsCheck and Diabetes MedsCheck services 2017 (Updated 2019). 
https://my.psa.org.au/s/article/Guidelines-for-pharmacists-providingMedsCheck-and-Diabetes-MedsCheck-services. Accessed Oct 12021

26. Pharmaceutical Society of Australia. Guidelines for pharmacists providing dose administration aid services. 2017. (Updated 2020). https://my.psa. org.au/s/article/Guidelines-for-pharmacists-providing-dose-administra tion-aid-services. Accessed Oct 12021

27. Pharmaceutical Society of Australia. Clinical Governance Principles for Pharmacy Services. 2018. https://www.psa.org.au/wp-content/uploads/ 2019/05/PSAClinicalGovernancePrinciples2018_FINAL.pdf. Accessed Oct 12021

28. Pharmaceutical Society of Australia. Guidelines for the Continued Dispensing of eligible prescribed medicines by pharmacists 2018 (Updated 2020). https://my.psa.org.au/s/article/Continued-dispensing-guidelines. Accessed Oct 12021

29. Pharmaceutical Society of Australia. My Health Record Guidelines for Pharmacists. 2019. https://www.psa.org.au/wp-content/uploads/2019/ 09/MHR-Guidelines-for-Pharmacists.pdf. Accessed Oct 12021

30. Pharmaceutical Society of Australia. Guidelines for Quality Use of Medicines (QUM) services. 2020. https://my.psa.org.au/s/article/guidelines-forqum-services. Accessed Oct 12021

31. Sansom LN (editor). Australian Pharmaceutical Formulary and Handbook 24th edition. Canberra Pharmaceutical Society of Australia; 2018.

32. Eysenbach G. Improving the quality of Web surveys: the Checklist for Reporting Results of Internet E-Surveys (CHERRIES). J Med Internet Res. 2004;6(3):e34

33. Pharmacy Board of Australia. Pharmacy Board of Australia Registrant data: Reporting period: 01 January 2020 to 31 March 2020. 2020. https://www. pharmacyboard.gov.au/about/statistics.aspx. Accessed Oct 12021

34. Nash RE, Chalmers L, Stupans I, Brown N. Knowledge, use and perceived relevance of a profession's Competency Standards; implications for Pharmacy Education. Int J Pharm Pract. 2016:24(6):390-402.

35. Gregory PAM, Austin Z. How do patients develop trust in community pharmacists? Res Soc Adm Pharm. 2021;17(5):911-20.

36. Gregory PAM, Austin Z. Understanding the psychology of trust between patients and their community pharmacists. Can Pharm J. 2021;154(2):120-8.

37. Jackson JK, Liang J, Page AT. Analysis of the demographics and characteristics of the Australian pharmacist workforce 2013-2018: decreasing supply points to the need for a workforce strategy. Int J Pharm Pract. 2021;29(2):178-85.

\section{Publisher's Note}

Springer Nature remains neutral with regard to jurisdictional claims in published maps and institutional affiliations.

Ready to submit your research? Choose BMC and benefit from:

- fast, convenient online submission

- thorough peer review by experienced researchers in your field

- rapid publication on acceptance

- support for research data, including large and complex data types

- gold Open Access which fosters wider collaboration and increased citations

- maximum visibility for your research: over $100 \mathrm{M}$ website views per year

At BMC, research is always in progress.

Learn more biomedcentral.com/submissions 